\title{
Evaluating genetic and genomic tests for heritable conditions in Australia: lessons learnt from health technology assessments
}

\author{
Sarah Norris $^{1}$ (D) $\cdot$ Andrea Belcher ${ }^{2,3}$ (D) Kirsten Howard $^{1}$ (D) $\cdot$ Robyn L. Ward $^{4,5}$ (D)
}

Received: 1 March 2021 / Accepted: 15 September 2021 / Published online: 27 September 2021

(c) The Author(s) 2021

\begin{abstract}
The Medical Services Advisory Committee (MSAC) is an independent non-statutory committee established by the Australian government to provide recommendations on public reimbursement of technologies and services, other than pharmaceuticals. MSAC has established approaches for undertaking health technology assessment (HTA) of investigative services and codependent technologies. In 2016, MSAC published its clinical utility card (CUC) Proforma, an additional tool to guide assessments of genetic testing for heritable conditions. We undertook a review and narrative synthesis of information extracted from all MSAC assessments of genetic testing for heritable conditions completed since 2016, regardless of the HTA approach taken. Ten assessments met our inclusion criteria, covering a range of testing methods (from gene panels to whole-exome sequencing) and purposes (including molecular diagnosis, genetic risk assessment, identification of congenital anomaly syndromes, and carrier screening). This analysis identified a range of methodological and policy challenges such as how to incorporate patient and societal preferences for the health and non-health outcomes of genomic testing, how best to capture the concept of co-production of utility, and how to engage clinicians as referrers for genomics tests whilst at the same time ensuring equity of access to a geographically dispersed population. A further challenge related to how qualitative assessments of patient and community needs influenced the evidence thresholds against which decisions were made. These concepts should be considered for incorporation within the value assessment frameworks used by HTA agencies around the world.
\end{abstract}

Keywords Genomics $\cdot$ Heritable $\cdot$ Health technology $\cdot$ Value $\cdot$ Evaluation $\cdot$ Cost

\section{Introduction}

Health technology assessment (HTA) is a multidisciplinary process that uses explicit methods to determine the value of a health technology at different points in its lifecycle,

This article is part of the Topical Collection on Resource Allocation in Genomic Medicine

Sarah Norris

sarah.norris@sydney.edu.au

1 Menzies Centre for Health Policy and Economics and School of Public Health, Faculty of Medicine and Health, University of Sydney, Sydney, NSW, Australia

2 Australian Genomics, Melbourne, VIC 3052, Australia

3 Faculty of Medicine, The University of Queensland, Brisbane, QLD 4072, Australia

4 University of Queensland, Brisbane, QLD, Australia

5 Faculty of Medicine and Health, University of Sydney, Sydney, NSW, Australia for the purpose of informing decision-making that promotes an equitable, efficient, and high-quality health system (O'Rourke et al. 2020). A health technology is any intervention developed to prevent, diagnose or treat medical conditions, promote health, provide rehabilitation, or organise healthcare delivery. A health technology can be a test, device, medicine, vaccine, procedure, service, program, or system.

HTA is a formal, systematic, and transparent process that uses state-of-the-art methods to consider the best available evidence (O'Rourke et al. 2020). An HTA typically considers the following: the health problem and current use of the technology; a description of the technology and its technical characteristics; safety; clinical effectiveness; an economic evaluation; an ethical analysis; relevant organisational aspects; patient and social aspects; and legal aspects (EUnetHTA 2016).

HTA is undertaken in many countries, by a range of government, not-for-profit, and commercial organisations, and has been used for more than four decades to inform clinical 
guidance, policy making, and funding (coverage) decisions (Banta and Jonsson 2009). Whilst the general approach to HTA is similar across countries, key differences do arise because of the perspective of the organisation undertaking the HTA, the perspective of the payer, and the features of the local health system (including its public and private health sector funding models).

\section{Health technology assessment in Australia}

In Australia, there are various funding schemes that provide public subsidy for pharmaceuticals, vaccines, medical services, devices, and tests. Reimbursement via public subsidy is assessed by one of three committees, each of which adopts an HTA approach. Assessment occurs after the national regulatory authority has approved the technology for marketing. One of these HTA committees, the Medical Services Advisory Committee (MSAC), is responsible for assessing genetic and genomic tests (see below). Requests for public subsidy must be initiated by a 'Sponsor', which can be any organisation or individual, but is typically a product manufacturer, service provider, clinical group, or a government entity. Details of these HTA processes are publicly available (Australian Government Department of Health 2020).

MSAC provides advice to the federal Minister for Health regarding the comparative safety, effectiveness, and costeffectiveness of a technology. If public subsidy for the technology is supported, one or more items will be established on the Medicare Benefits Schedule (MBS) which describe the service that is subsidised and an MBS fee that reflects the costs and resources required to deliver the service. For a medical test on the MBS, the fee would reflect the consumables and the time of the relevant health professional(s) to collect, prepare, analyse, and report on the biological specimen.

\section{Health technology assessment of genetic tests in Australia}

MSAC has well-established processes and methods for undertaking HTA of medical tests, including genetic tests. The standard MSAC approach for evaluating tests is detailed in technical guidelines for the assessment of investigative services (Medical Services Advisory Committee 2017), which also includes specific guidance for assessing companion diagnostics (referred to in Australia as 'codependent technologies'). Many assessments of genetic tests for somatic pathogenic single gene variants have been undertaken by MSAC, typically for the purpose of establishing eligibility for subsidised pharmaceuticals, for example, $A L K$ rearrangement testing in patients with non-small cell lung cancer to determine eligibility for crizotinib (Medical Services Advisory Committee 2013), or RAS mutation testing for eligibility for panitumumab in metastatic colorectal cancer (Medical Services Advisory Committee 2014).

However, early applications to MSAC for genetic tests for heritable conditions highlighted deficiencies in the guidelines for investigative services and codependent technologies. For example, MSAC deferred a funding decision for cystic fibrosis transmembrane regulator testing because issues specific to genetic/genomic testing were not addressed (Medical Services Advisory Committee 2015b). These included eligibility for testing, genetic counselling requirements, the impact of undertaking testing in biological relatives (cascade testing), the role of routine antenatal screening for reproductive planning, and the likely impact of next-generation sequencing (NGS). Similarly, an application for pre-implantation genetic diagnosis (PGD; Medical Services Advisory Committee 2015a) was deferred by MSAC with the committee noting the absence of data on psychological distress from prenatal testing, consumer preference for prenatal testing versus PGD, and the risks associated with termination of pregnancy. MSAC also noted that nonmedical considerations, such as psychological, ethical, and social issues, and the management of genetic risk were not adequately addressed.

\section{Development of a new assessment framework for tests for heritable conditions}

MSAC established a Predisposition Genetic Testing Working Group (the Working Group) to develop and pilot an HTA approach for assessing genetic and genomic testing for heritable conditions. The Working Group was convened from 2015 to 2016 and included individuals with a range of experience in clinical or molecular genetics, health economics, MSAC processes and methods, and representatives of the Royal College of Pathologists of Australasia (RCPA). A scoping review of international approaches to the assessment of genetic tests identified the EuroGentest clinical utility gene card (Schmidtke and Cassiman 2010), and the ACCE evaluation process for genetic testing: analytical validity, clinical validity, clinical utility, and ethical, legal, and social implications (Burke et al 2002). The Working Group combined the domains from these two assessment tools with the HTA domain of costs and economic evaluation to develop the clinical utility card (CUC) Proforma (Medical Services Advisory Committee, 2016a). The CUC Proforma was piloted with Application 1411-testing for BRCA1/2 germline pathogenic variants in people with breast or ovarian cancer-and subsequently revised following re-assessment of this application (i.e. Application 1411.1). 
Importantly, the CUC Proforma was constructed from a clinical perspective of disease management, to allow determination of the populations to be tested (affected individuals and their family members) and characterisation of the consequences of testing (potentially over long timeframes). As the name suggests, it places an emphasis on clinical utility, which was defined for MSAC purposes as testing which yields an actionable result which in turn leads to changes in health outcomes in affected individuals and/or their biological relatives. The CUC Proforma introduced three key concepts for HTA undertaken by MSAC: (i) the importance of selecting individuals for testing based on the likelihood that they harbour heritable pathogenic variants (referred to as the pre-test probability of pathologic heritable mutation(s)), (ii) 'star performer' genes, and (iii) the co-production of healthrelated utility that occurs when family members experience positive health outcomes.

MSAC's preference for an actionable genetic test result was reflected in the CUC Proforma requirement for a pre-test clinical assessment of at least a $10 \%$ likelihood of pathogenic variants in the 'star performer' gene(s) in the affected individual. This pre-test probability threshold was introduced to avoid testing in populations with a high probability of an uninterpretable or unactionable result (i.e. genetic testing with low clinical utility).

'Star performer' genes were defined as high penetrance, actionable gene(s) within a disease area that are likely to have the clearest evidence of clinical utility, and which will consequently have the strongest cost-effectiveness argument. A request for public funding could include additional relevant genes (i.e. genes with sufficient penetrance included in well-regarded clinical practice guidelines), but a lower threshold of evidence would be applied to these. Co-production of health-related utility recognises that any value of cascade testing in family members can only accrue if probands have been tested. This is important for the economic evaluation of cascade testing, as it means the marginal cost-effectiveness of testing family members must be derived from a comparison of the cost-effectiveness of testing affected individuals and testing family members of probands versus the cost-effectiveness of only testing affected individuals.

\section{Selecting the approach for an MSAC application}

Before applying to MSAC, sponsors have the option of participating in one or more pre-submission meetings with the Department of Health, to discuss how they will frame their application. The selection of a specific assessment approach for an application is not rules based: sponsors are free to choose which approach they will apply, and the investigative services guidelines and codependent technology guidelines can be used for any type of test. For genetic or genomic testing, any one of the three assessment approaches may be appropriate: the CUC Proforma approach when testing is likely to be required in biological relatives as well as index cases; the codependent technologies approach when the results of testing can rule in or rule out the use of a particular pharmaco- or immunotherapy; and the investigative services approach for all other purposes.

Since 2015, each of the three approaches (investigative services, codependent technologies, and the CUC Proforma) has been used to frame assessments of genetic or genomic testing for heritable conditions. The aim of this paper was to review MSAC's experience assessing tests for this purpose, regardless of the HTA approach used, and share current thinking regarding the need for further evolution of MSAC's approach to the assessment of genetic and genomic testing for heritable conditions, and for genomic testing more broadly.

\section{Methods}

\section{Study selection and inclusion criteria}

All applications listed on the MSAC website were searched by two authors ( $\mathrm{AB}$ and $\mathrm{SN}$ ) to identify potentially relevant applications. Applications were included for review if they met the following criteria: were for a genetic or genomic test for a heritable condition; were considered by MSAC at or after their March 2016 meeting (when the CUC Proforma was available); and there was a public summary document (PSD) available on the MSAC website at the time of the initial (January 2021) or updated search (April 2021). A PSD describes the rationale and funding advice from MSAC to the Minister for Health, together with a summary of the full HTA report. Sometimes information considered by the sponsor to be commercial-in-confidence will be redacted in the PSD.

\section{Data collection and analysis}

For each included application information from the relevant PSD(s) was initially extracted into a data extraction form by $\mathrm{AB}$ followed by checking and completion of the data extraction by SN.

The following data were extracted: the defining characteristics of the initial population(s) to be tested; the purpose of testing (as per Korf and Irons 2012); the 'scale of testing' (which describes the comprehensiveness of sequencing, from more targeted sequencing (e.g. small gene panels) to more comprehensive sequencing (WES or WGS)); the date of the most recent consideration by MSAC; the HTA approach used (i.e. CUC Proforma, investigative services, or 
codependent technologies); the type of economic evaluation relied on by MSAC; the key measure(s) of cost-effectiveness relied on by MSAC; MSAC's assessment of the net costs to government likely to be associated with public funding for the proposed test; MSAC's overall judgement of value; and whether the application was supported or not supported by MSAC. All monetary values are expressed in Australian dollars and reflect the year in which each assessment was undertaken. Dollar values have not been converted to a single year given the short timeframe of analysis (2016 to 2020). In addition, key challenges faced by MSAC during their appraisal were extracted from the PSDs and organised by theme.

A narrative synthesis was performed to compare the general features and evaluation components of the applications. The authors then individually and collectively reflected on the data to describe how MSAC's view of its information needs has evolved over time in response to the diversity of applications assessed. The quality of the individual applications has not been appraised as part of this review as all contracted assessments and PSDs are prepared according to quality standards monitored by the Australian Department of Health. Where key pieces of information were missing from a PSD, this information was requested from the Department of Health and provided to us when appropriate to do so.

\section{Results}

\section{Characteristics of selected studies}

A total of ten applications, considered by MSAC between March 2016 and November 2020, met our study inclusion criteria (see Table 1). All published documents associated with an application were reviewed for relevant information, in particular: one application (breast and ovarian cancer) has two PSDs, an original application (1411), and a resubmission (1411.1), and the most recent assessment for noninvasive prenatal testing (NIPT) was application 1492, but earlier requests for this service had been initiated (1458 and 1461). Each included application was categorised according to the main purpose of testing the initial target population(s): three applications have been for 'identification of congenital anomaly syndrome' (childhood syndromes, NIPT, and foetal structural anomalies); two applications have been for 'genetic testing for risk of cancer' (breast and ovarian cancer, and colorectal and endometrial cancer risk); two applications for 'molecular diagnosis of genetic disorder' (Alport syndrome, and cardiac arrhythmias); and one application for each of 'genetic risk assessment' (familial hypercholesterolaemia), 'pharmacogenomics' (Ovarian BRCA1/2 for olaparib), and 'carrier screening' (carrier testing for cystic fibrosis (CF), spinal muscular atrophy (SMA), and fragile
$\mathrm{X}$ syndrome (FXS)). The type of testing varied across the ten applications, from targeted gene panels to whole-exome sequencing and genome-wide microarray.

Table 2 presents key aspects of the HTA approach taken for the ten applications. All but one of the applications (NIPT) was ultimately supported by MSAC for public funding. Six applications used the CUC Proforma to frame the HTA, three applications used the investigative services approach, and one used the codependent technologies approach. A cost-utility analysis (CUA) was undertaken for four applications, and a cost-effectiveness analysis (CEA) was undertaken for five applications. In one application, the economic analysis was deemed by MSAC to be unreliable (Alport syndrome).

Where the base-case incremental cost-effectiveness ratio (ICER) has been published for the CUAs, it ranged from $\$ 7,254$ per quality-adjusted life year (QALY) to $\$ 24,907 /$ QALY. Assessments that relied on a CEA used a variety of units to express cost-effectiveness: cost per pathogenic variant detected (specific mutations, copy number variants, or presence of trisomy), cost per complex birth avoided, or cost per carrier couple detected. Although these ICERs cannot be directly compared because of the different units used, it was noted that the requests where testing was dominant or yielded an ICER less than $\$ 10,000$ per outcome were ultimately supported by MSAC, whereas the testing that was not supported by MSAC (NIPT) was associated with an ICER of more than $\$ 500,000$ per outcome. For the eight applications that were supported by MSAC and for which the government budget impacts are reported, the financial estimates ranged from less than $\$ 1 \mathrm{M}$ per annum to less than $\$ 10 \mathrm{M}$ per annum. For the one assessment that was not supported by MSAC (NIPT), the financial estimate was in the order of $\$ 100 \mathrm{M}$ per annum.

For eight of the applications MSAC's judgement of value relied primarily on clinical utility to affected individuals and/or their family members (typically through avoidance of further diagnostic tests, changes in disease risk management, or the avoidance of unnecessary treatments), and in the remaining two applications, it relied on reproductive confidence for the tested individuals.

Figure 1 presents the applications arranged by key features of the tested populations: symptomatic or asymptomatic and broad age group (prenatal, paediatric, adult). Figure 2 shows the applications organised by purpose of testing and type of HTA approach used. The figures illustrate the diversity of populations and testing purpose reflected in the ten applications. Eight out of ten applications were for initial testing in populations that were symptomatic (although cascade testing could have been in asymptomatic family members), and seven applications were for initial testing in adults (Fig. 1). The CUC Proforma approach was used for applications concerned with genetic testing for risk of 


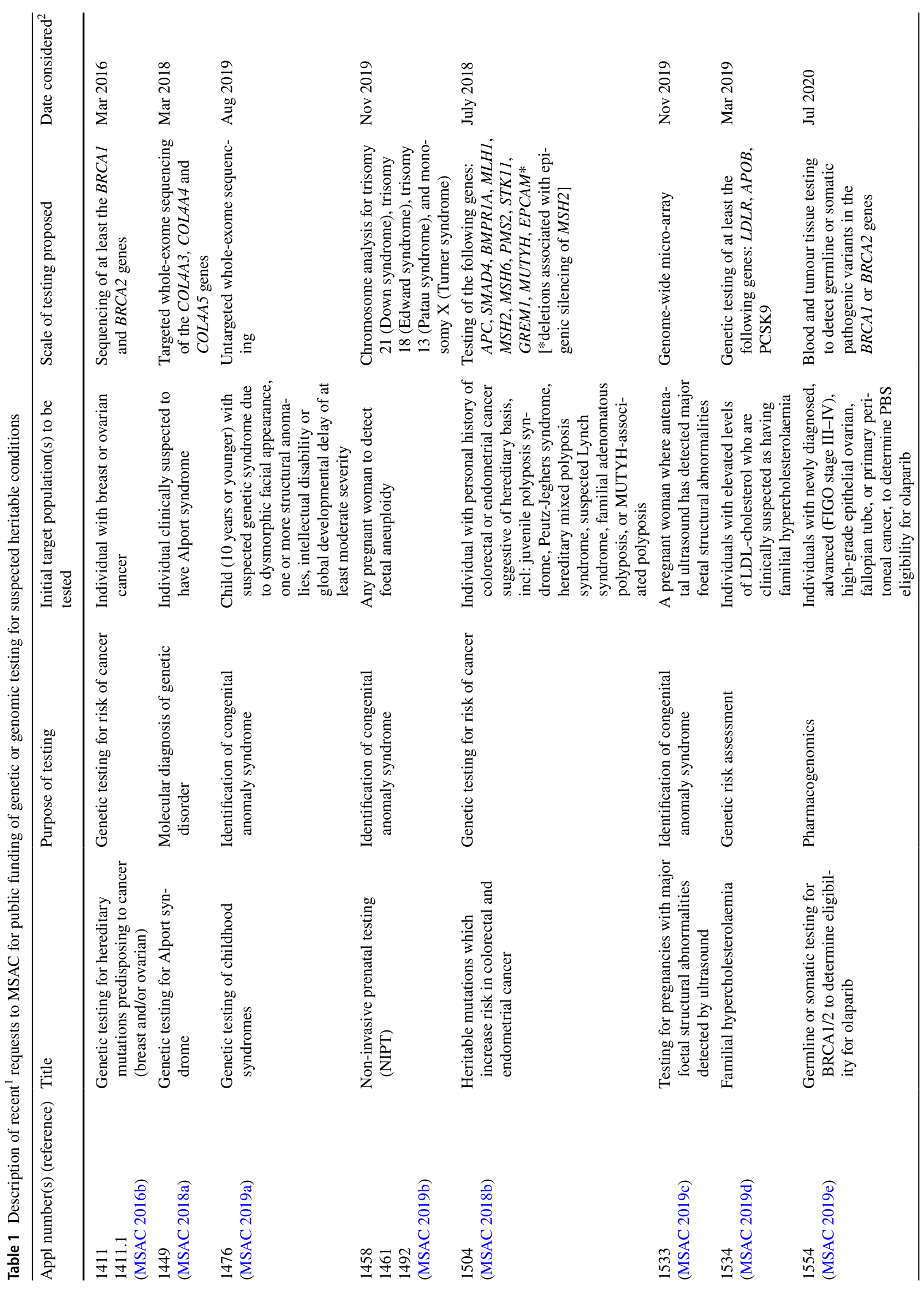




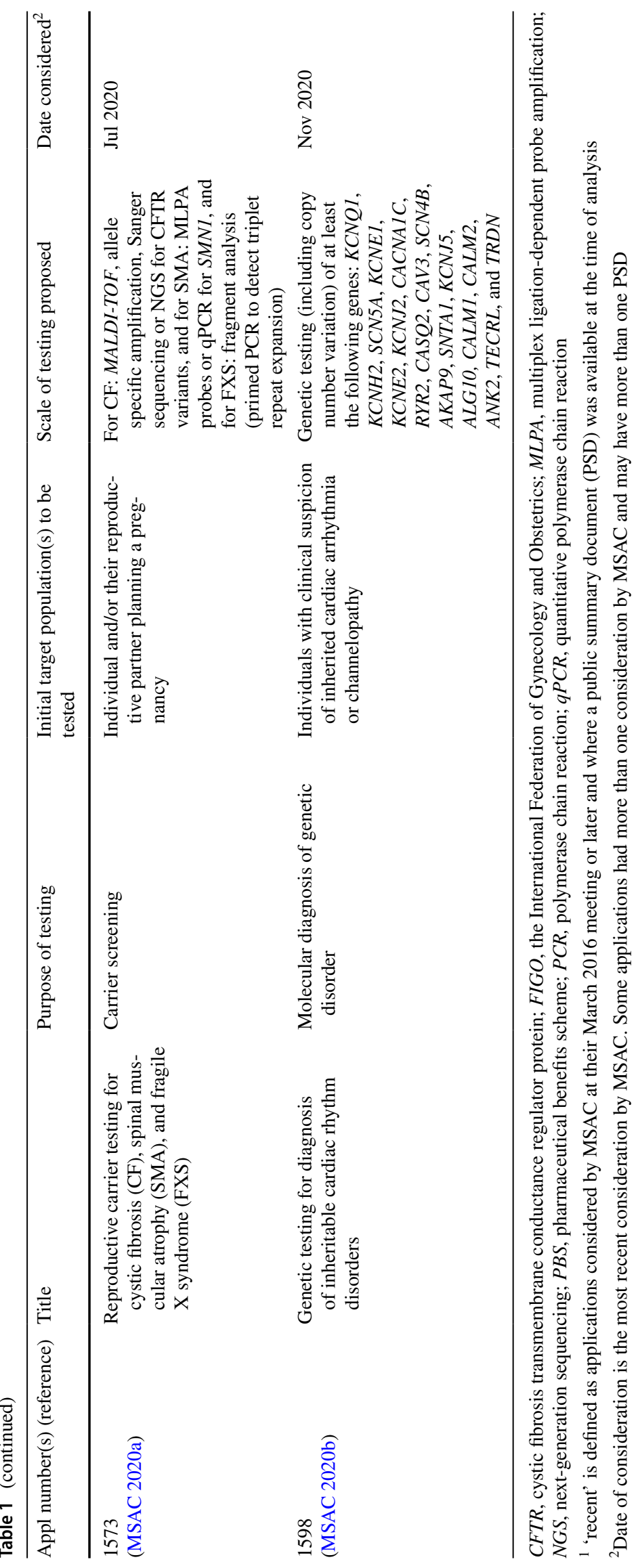




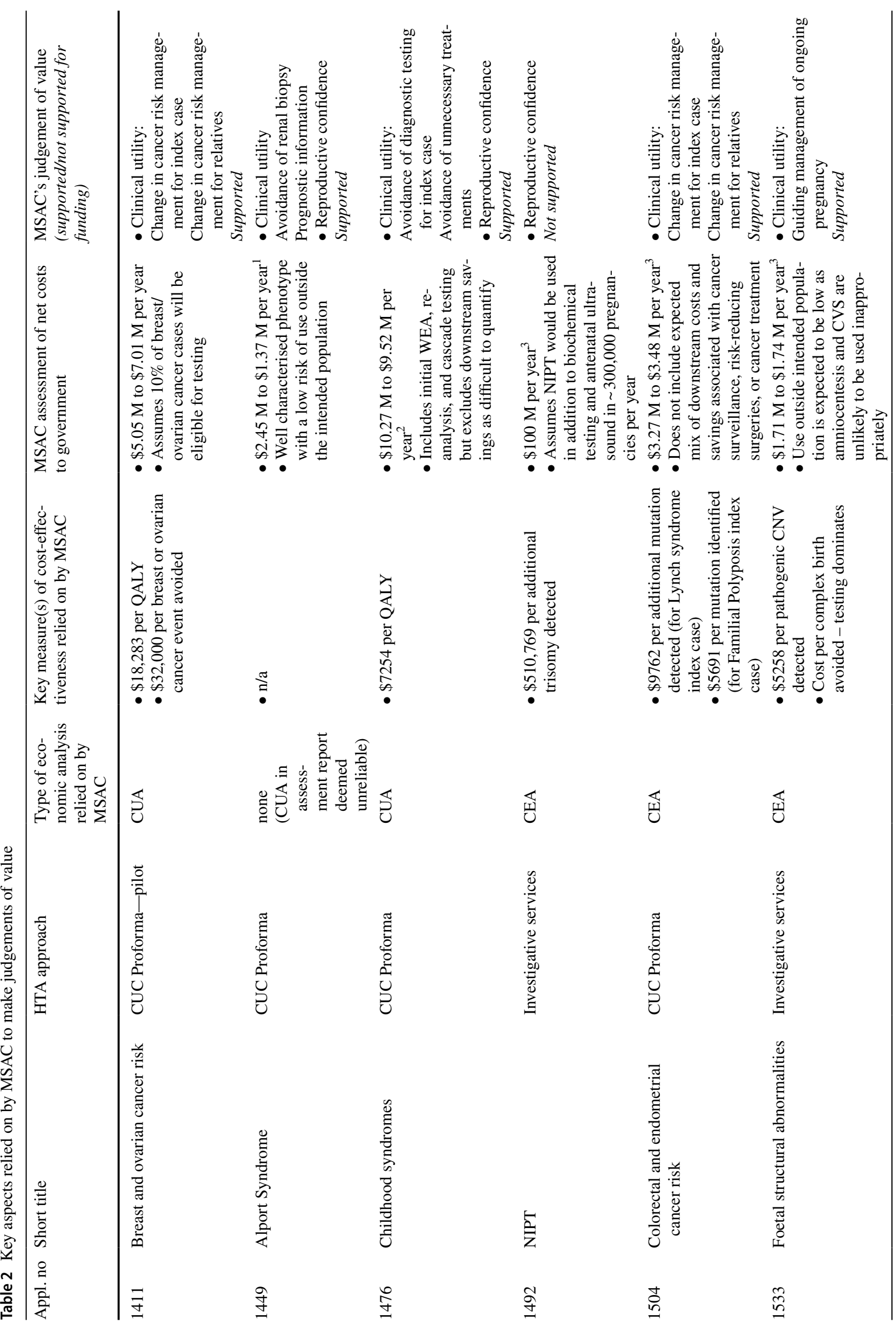




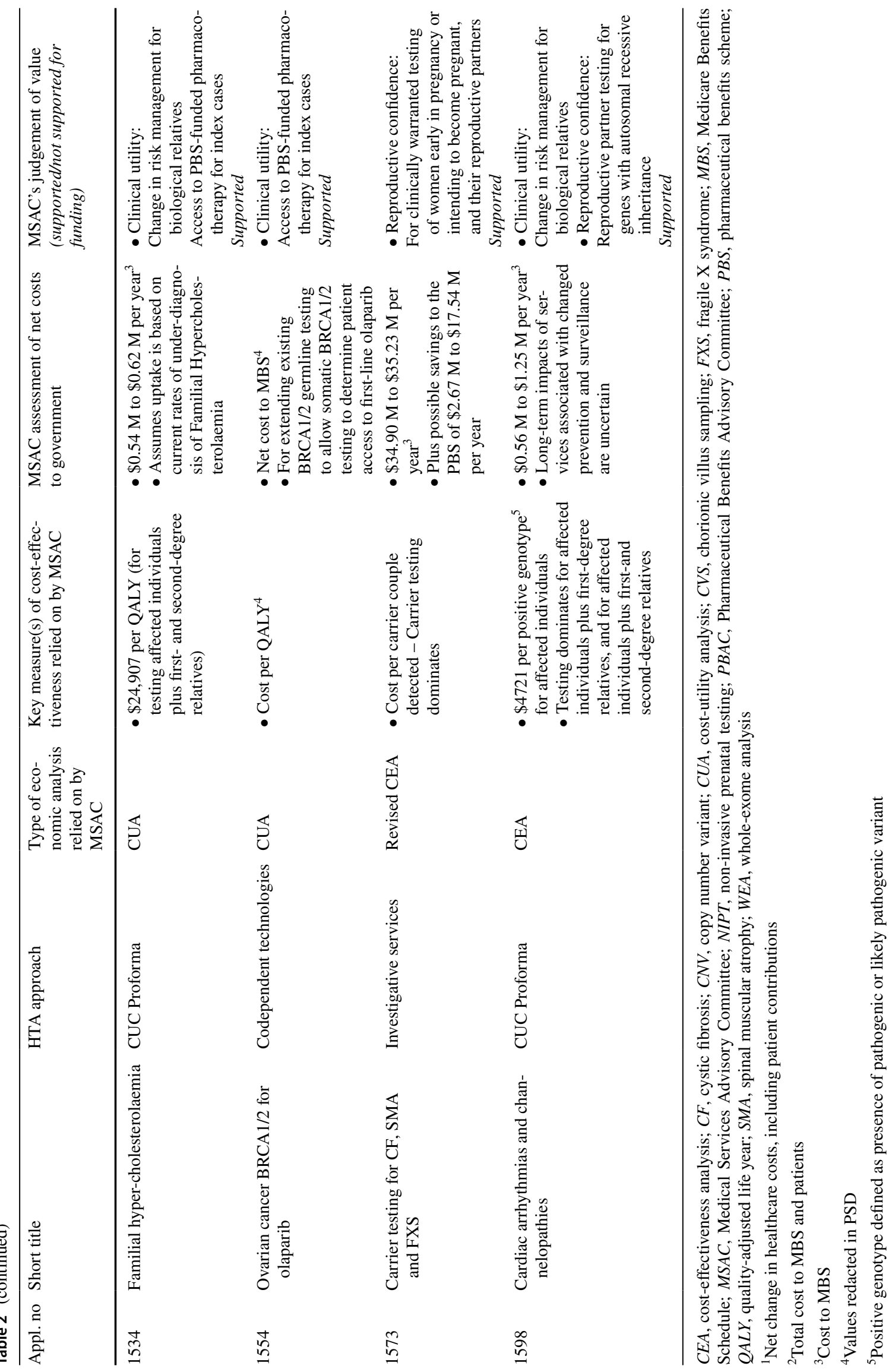


Fig. 1 MSAC applications by features of the primary population for testing. Note: Application 1449 appears twice as testing of affected individuals can be undertaken in children or adults. Abbreviations: $\mathrm{CF}$, cystic fibrosis; CUC, clinical utility card; Fragile X, fragile $\mathrm{X}$ syndrome; MSAC, Medical Services Advisory Committee; NIPT, non-invasive prenatal testing; SMA, spinal muscular atrophy

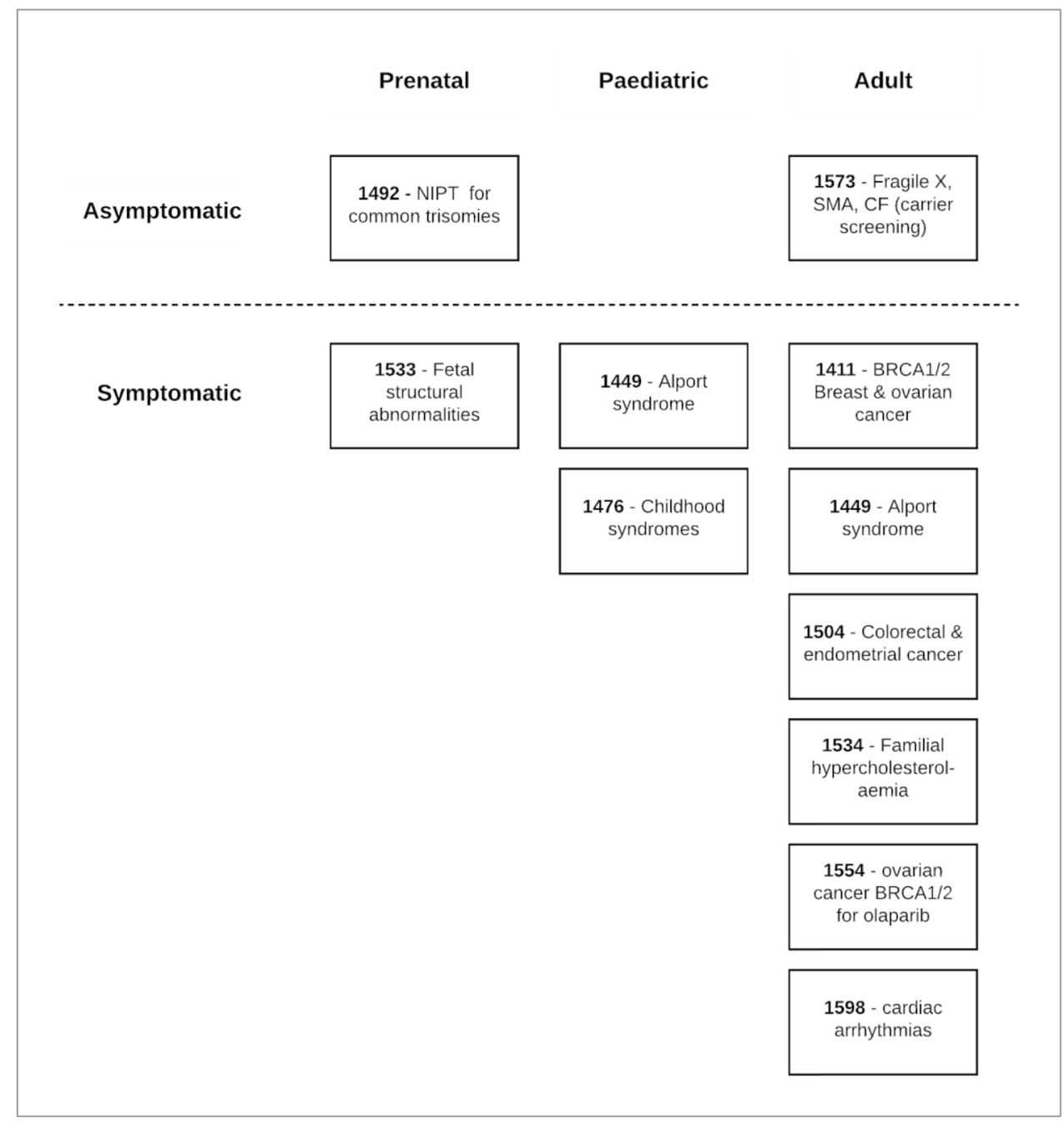

cancer, genetic risk assessment, or molecular diagnosis of a genetic disorder. Applications for the purpose of identifying a congenital anomaly syndrome used either the CUC Proforma or the investigative services approach. The single application concerned with carrier screening used the investigative services approach, and the single application for testing for a pharmacogenomics purpose used the codependent technologies approach.

\section{Synthesis of findings}

The lessons learnt by MSAC during the assessment of the ten applications are summarised by theme in Table 3 . These themes reflect the HTA domains across the CUC Proforma and the MSAC guidelines for investigative services and codependent technologies. Specific aspects that were challenging for assessment are listed, together with the approach taken by MSAC to address these challenges. A summary of the approaches adopted in assessing application 1504 is presented as Fig. 3, to illustrate some of the key themes. These themes are described in more detail below.

\section{Health condition}

Clinical validity (the link between a genotype and a disease or disease risk) was easier to assess in circumstances with a limited number of involved genes and a specific phenotype (e.g. Alport syndrome), but harder to assess when there were multiple involved genes and a non-specific phenotype (e.g. Childhood syndromes), or when the condition was rare (e.g. Peutz-Jeghers syndrome). For some applications, MSAC redefined the populations to be assessed and used evidence of effectiveness, safety, and cost-effectiveness in one population to infer effectiveness, safety, and cost-effectiveness in a clinically related population. For example, application 1411 was underpinned by the evidence linking BRCA1/2 testing in breast cancer probands, and this was used to support public funding for BRCA $1 / 2$ testing in breast cancer probands and ovarian cancer probands. In application 1504, 
Fig. 2 MSAC applications by purpose of testing and HTA approach used. Abbreviations: CF, cystic fibrosis; CUC, clinical utility card; Fragile X, fragile X syndrome; MSAC, Medical Services Advisory Committee; NIPT, non-invasive prenatal testing; SMA, spinal muscular atrophy

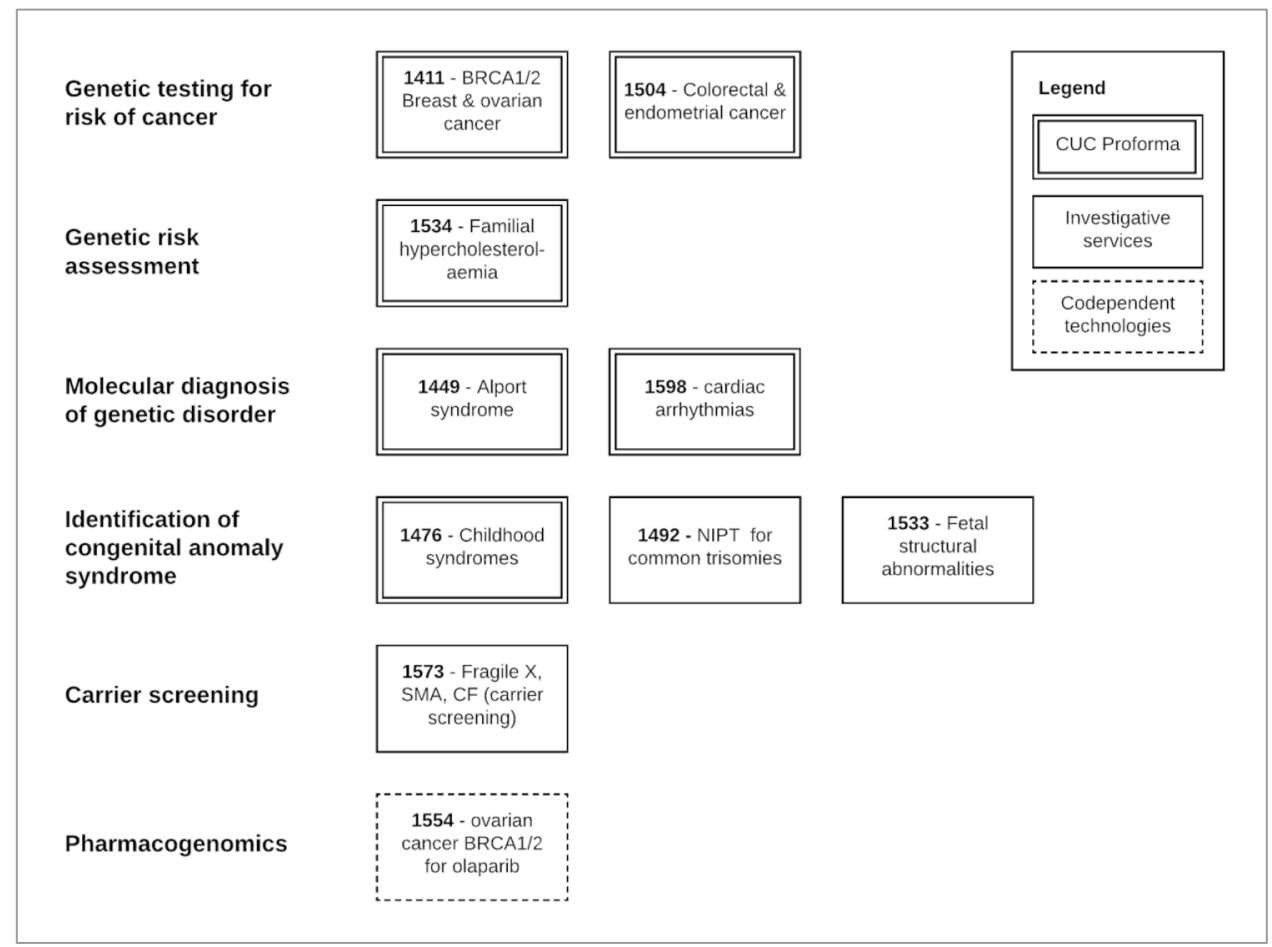

a heterogenous population of individuals with suspected heritable colorectal or endometrial cancer was redefined as three patient groups which better reflected the linkage between genotype and condition (see Fig. 3). Evidence of the effectiveness, safety, and cost-effectiveness of genetic testing for Lynch syndrome in colorectal cancer probands was then used to inform public funding decisions for genetic testing for Lynch syndrome in endometrial cancer probands and genetic testing for five familial polyposis syndromes.

\section{Pathways of care}

Many applications focused on the genetics of the condition(s) in question and the technical performance of the genetic/genomic test (see below), without sufficient consideration of how and when an individual would be considered for testing (i.e. prior testing), the type of health professional who would request the test, and whether the proposed test would replace or be used in addition to current testing. MSAC typically referred to evidence-based clinical practice guidelines to better understand the likely pathways of care, with and without the proposed test (e.g. 1504, 1598).

The most appropriate place in care for genetic/genomic testing was most difficult to define when the testing was proposed for asymptomatic individuals (see Fig. 1): prenatal screening (1492) and carrier screening for rare diseases (1573). The challenges included different views held by different clinical specialities; established use of biochemical methods with acceptable accuracy and cost; established uptake of genomic testing in the private sector; and different funding responsibilities between the federal and state governments. Similar challenges have been discussed by Cornel et al. (2021), who describe how innovations in sequencing technology are challenging established principles for screening.

As noted in the "Introduction", MSAC's preference for limiting germline testing to populations with a higher likelihood of an actionable result is reflected in the requirement for $\mathrm{a}>10 \%$ pre-test probability that an individual will harbour pathogenic variants in one or more specified genes. Although the selection of this threshold was questioned by sponsors, it has been very helpful in defining the proposed population for testing by more explicitly articulating the clinical presentation and findings from prior tests.

\section{Technology}

MSAC found that analytic validity was difficult to ascertain when multiple molecular techniques can be used in different combinations, and the studies of test performance do not always describe the techniques used. To address this, MSAC assessed the available evidence and then tended to assume $100 \%$ sensitivity and specificity for the corresponding economic evaluations. Over time, MSAC has placed more focus on the diagnostic yield of a test, the applicability of the available evidence to the proposed use of the test in Australian clinical practice, and the relative clinical importance of different diagnostic yields. 


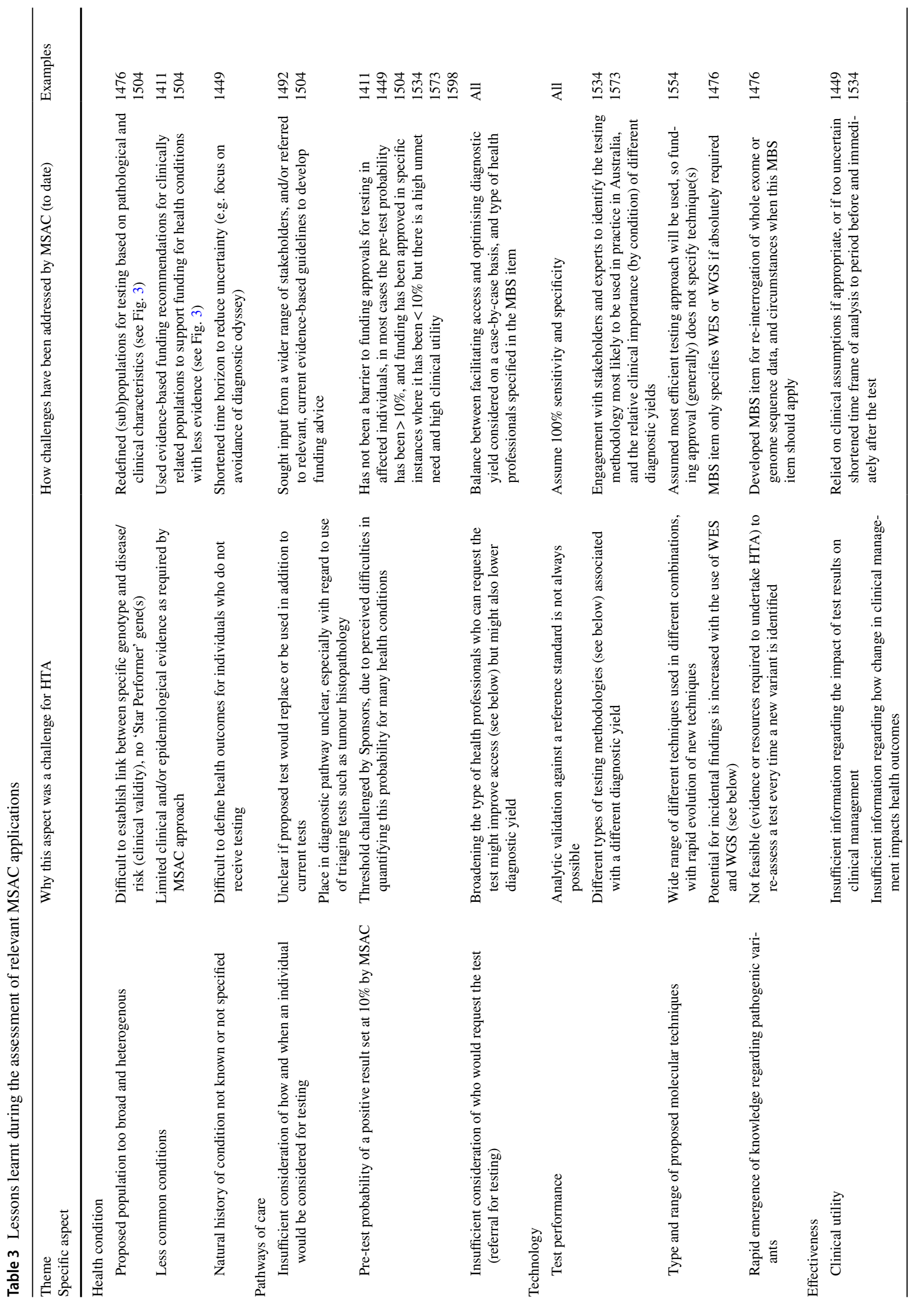




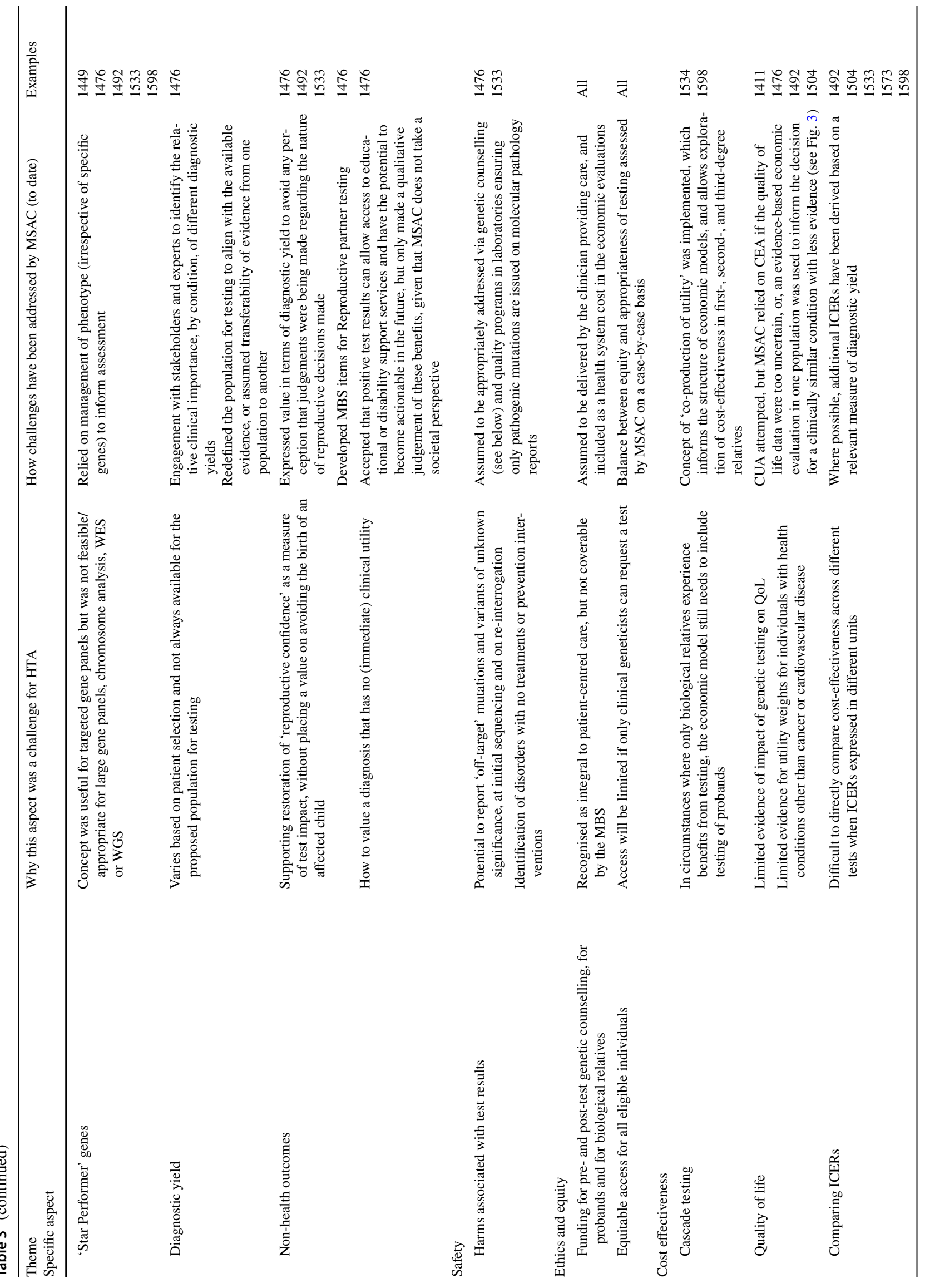




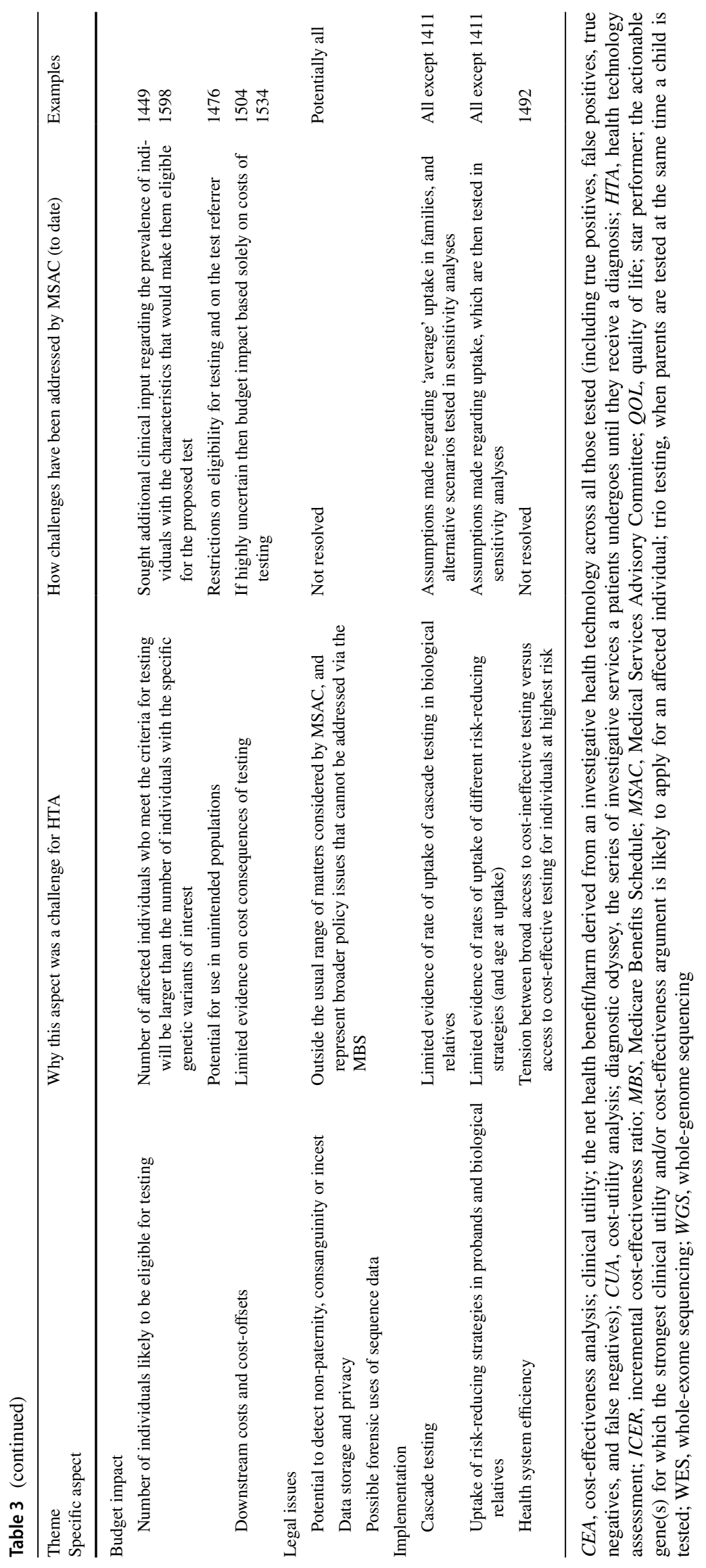


Fig. 3 Example showing how evidence and economic evaluations from one population were accepted by MSAC as the basis for funding approval for clinically related populations with less evidence. Abbreviations and definitions: $\mathrm{CRC}$, colorectal cancer; EC, endometrial cancer; FAP, familial adenomatous polyposis; HMPS, hereditary mixed polyposis syndrome; JPS, juvenile polyposis syndrome; LS, Lynch syndrome; MAP, MUTYH-associated polyposis; MBS, Medicare Benefits Schedule; MSAC, Medical Services Advisory Committee; PJS, Peutz-Jeghers syndrome; star performer, defined by MSAC as high penetrance, actionable gene(s) within a disease area that are likely to have the clearest evidence of clinical utility

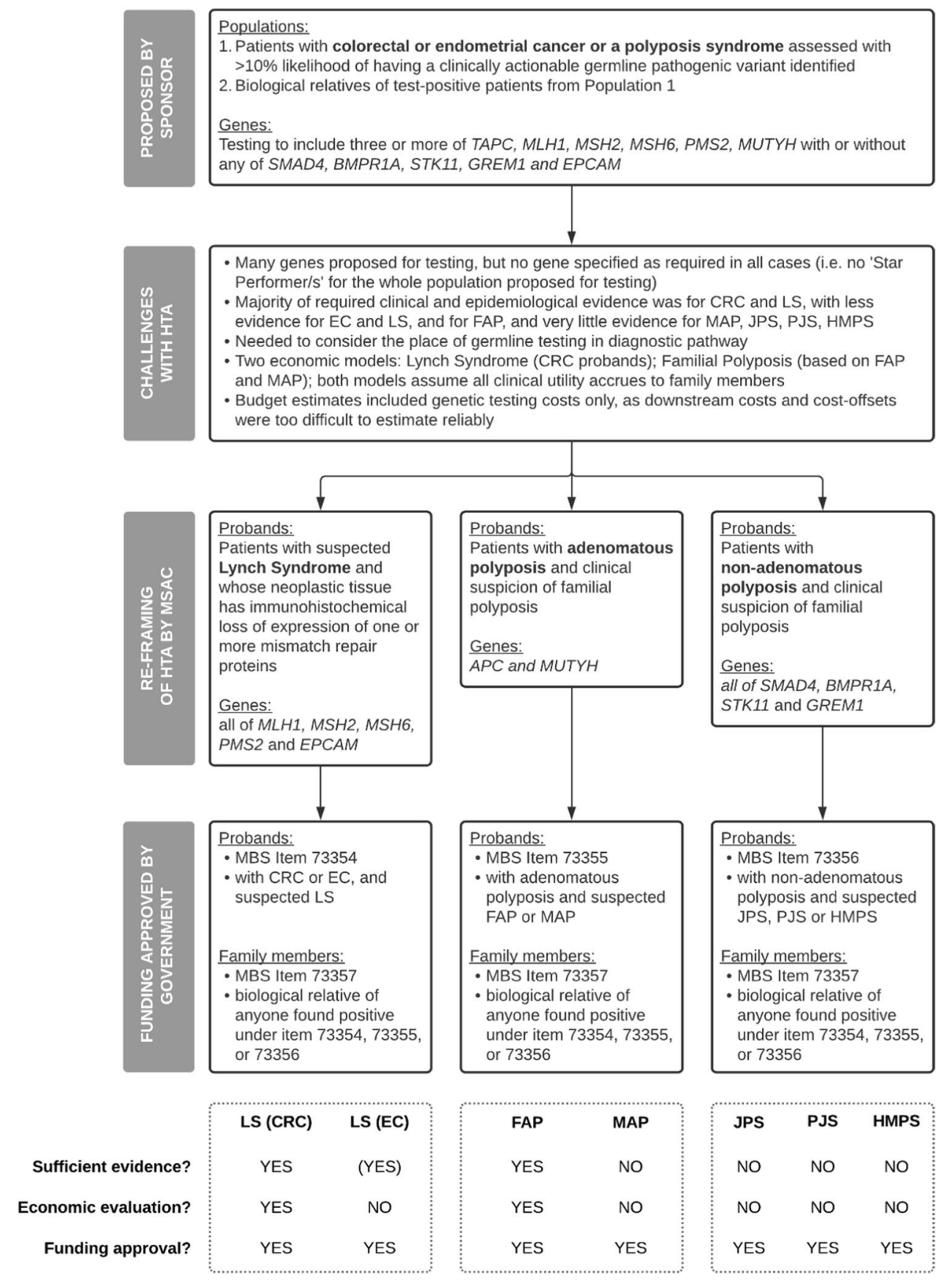

It is well-known that genetic/genomic testing is undergoing a high rate of technological innovation with a concurrent rapid increase in the knowledge base of genes involved in disease. The dynamic features of this class of health technology are challenging for HTA, which is essentially a static assessment (i.e. at a point in the product life cycle). MSAC has sought to address the first aspect, rapid technological innovation, by make funding approvals largely agnostic to the molecular technique(s) used, in order to 'future proof' the MBS items as much as possible. The second point has been addressed in two ways: (i) limiting the evidence assessment requirements to a small number of genes per heritable condition, but then recommending funding for a broader list of genes for that condition (i.e. the 'Star performer gene' concept), and (ii) developing MBS items for future re-interrogation of sequencing data, where appropriate.

\section{Effectiveness}

As noted above, applications tended to focus on the technical performance of a test, and in many instances, there was 
limited evidence regarding the impact of test results on clinical management and/or health outcomes. This made it challenging to establish clinical utility for a test, either directly or indirectly, through the use of linked evidence. Rather than reject requests for funding on the basis of a failure to demonstrate clinical utility, MSAC sought to base its advice on assumptions regarding the impact of test results. If these assumptions were highly uncertain, MSAC reduced the uncertainty by shortening the time horizon of the analysis to the period before and immediately after the test $(1449,1534)$. Ultimately, the demonstration of clinical utility was the basis of decision-making for eight of the nine applications that received funding approval. In two of these eight applications $(1534,1598)$, the clinical utility accrued entirely to the biological relatives of the affected individuals/probands.

MSAC has attempted to place a value on two of the potential non-health outcomes of genetic or genomic testing: restoration of reproductive confidence and providing a diagnosis that has no immediate clinical utility. In five applications $(1449,1476,1492,1573,1598)$ reproductive confidence was judged by MSAC to be an important measure of test effectiveness. In some assessments, attempts were made to predict the reproductive choices that would be made with and without the test results, but MSAC found these predictions to be highly uncertain. Moreover, MSAC was acutely aware that the outcomes associated with reproductive decisions (e.g. using in vitro fertilisation methods, pregnancy termination, giving birth to an affected child) are valued differently by different individuals. Consequently, MSAC elected to express value in terms of diagnostic yield, such as the number of additional trisomies detected (1492) or the number of carrier couples detected (1573). MSAC acknowledged that both negative and positive test results can inform reproductive decisions, but expressing cost-effectiveness in terms of the cost per 'informed reproductive decision' would produce ICERs that are uninformative for MSAC as they would simply equate to the cost of the test.

The value of providing a diagnosis with no immediate clinical utility is exemplified by application 1476 and WES for the diagnosis of childhood syndromes. In its consideration, MSAC acknowledged that there was value in receiving a confirmed molecular diagnosis as, in addition to restoring reproductive confidence, it likely ended the diagnostic odyssey for the family and could allow access to educational or disability support services. Evidence consistent with this conclusion was later published: a discrete choice experiment found that members of the Australian public highly valued the non-clinical components of genomic sequencing in complex paediatric neurological disorders (Goranitis et al 2021).

\section{Safety}

As with all investigative services assessed by MSAC, each genetic or genomic test was evaluated for safety in terms of the methods used to collect the biological specimen for testing (e.g. blood sample, tissue biopsy). In addition, MSAC recognised that genetic and genomic testing have the potential to cause psychological harm to the individuals undergoing testing. This harm can arise through the identification of 'off target' mutations or non-actionable genetic variants (variants of unknown significance, or variants with no known treatment). Harms can also arise as a consequence of detecting non-paternity, consanguinity, or incest (see "Legal issues" below).

The importance of measuring the impact of genetic testing using patient-centred outcomes has been recognised internationally for many years, but there are very few highquality studies that describe these impacts (Phillips et al. 2017). Psychological impacts that are measurable using validated tools could be included in any MSAC application, but to date, none of the applications considered by MSAC has incorporated this potential impact of testing.

\section{Ethics and equity}

A recurring challenge across the MSAC assessments was how best to capture the requirements for pre- and post-test genetic counselling. Whilst MSAC accept that genetic counselling is an integral part of patient-centred care, it is not coverable as a stand-alone service on the MBS (due to legislative constraints). This challenge was managed by MSAC in a 'technical' sense by assuming that the clinician referring the individual for testing would provide the required counselling and by including the costs for delivering genetic counselling within the economic evaluations.

Ensuring equity of access to safe, effective, and costeffective care is a key principle that guides the development of all MSAC advice. For each application, MSAC explicitly considered which health professionals would be eligible to request an MBS-funded test, recognising the limited number of clinical geneticists in Australia. In doing this, MSAC sought to find a balance between increasing the access to testing (by broadening the range of requestors) whilst maintaining diagnostic yield (i.e. effectiveness).

\section{Cost-effectiveness}

As reported by Phillips et al. (2018), key challenges for MSAC in assessing economic evaluations have fallen into three domains of complex model structures (to capture the multiple pathways of use of testing), the measurement of costs and outcomes, and a lack of good quality data. When there was a high level of uncertainty regarding the 
downstream consequences of testing due to a paucity of reliable evidence, MSAC tended to rely on a CEA (instead of its preference for a CUA, e.g. 1449,1534) and/or a shorter time horizon for the assessment (namely, a focus on the pathway of care prior to and immediately after testing; e.g. 1504, 1598). In one application (1449), MSAC essentially relied on a cost-consequence analysis and noted that 'while the evidence base for genetic testing [in Alport syndrome] was limited, there was acceptable evidence of clinical safety and effectiveness, and the financial impact of funding was likely to be low in the context of this rare disease with a well-characterised phenotype'.

In other circumstances $(1504,1598)$ there was so little evidence that even an economic evaluation with a short time horizon could not be reliably developed. In these situations, demonstration of cost-effectiveness in a clinically similar population was accepted by MSAC as being broadly applicable to the population with insufficient evidence. This is illustrated in Fig. 3: evidence-based costeffectiveness of testing probands with colorectal cancer and suspected Lynch syndrome was used to support funding for probands with endometrial cancer and suspected Lynch syndrome, and evidence-based cost-effectiveness for testing individuals with suspected familial adenomatous polyposis (FAP) was used to support funding for individuals suspected as having MUTYH-associated polyposis (MAP), juvenile polyposis syndrome (JPS), Peutz-Jeghers syndrome (PJS), or hereditary mixed polyposis syndrome (HMPS).

As noted above, the demonstration of the clinical utility of testing for probands and/or biological relatives was the primary basis for MSAC decision-making: for two applications, clinical utility accrued entirely to the biological relatives $(1534,1598)$. Applying the concept of co-production of health-related utility was important for all these applications, especially the latter two, as it provided a consistent framework for structuring and reporting the economic evaluations. This approach to the economic evaluations also framed marginal analyses to explore the relative cost-effectiveness of extending testing beyond first-degree relatives to second- and third-degree relatives (e.g. 1534).

The challenges encountered by MSAC in assessing the costs and cost-effectiveness of genetic and genomic testing are similar to those reported by others. A systematic review of the health economic evidence for genetic and genomic testing (across a range of clinical purposes similar to those described herein) found that few studies reported data transparently and/or did not state which components were included in cost estimates (Schwarze et al. 2018). Like MSAC, these authors found there was a very limited body of evidence regarding the impact of genetic/genomic tests on intermediate or final health outcomes.

\section{Budget impact}

A common challenge with establishing budget impact estimates was determining the number of individuals likely to be eligible for testing. Many applications provided information on the prevalence of specific genetic variants, but provided little or no information on the (larger) number of individuals suspected as having those variants, or the extent of testing uptake in biological relatives. MSAC addressed these issues in a technical sense (by testing assumptions regarding eligible population size in sensitivity analyses) and via implementation (i.e. proposing MBS item descriptors with clear criteria for testing).

In applications where there was high degree of uncertainty regarding downstream costs and consequences of testing, MSAC relied on assessments of budget impact that were limited to the costs of delivering testing (i.e. the genetic/ genomic test itself, plus any other tests or services required to deliver the test; e.g. 1504, 1534).

\section{Legal issues}

In addition to the ethical issues noted above, MSAC has acknowledged legal issues that might arise as consequence of genomic testing, including data storage and privacy, possible forensic uses of sequencing data, and the potential to detect non-paternity, consanguinity, or incest. These matters have not been addressed by MSAC as they represent broader policy issues that fall outside the remit of the committee.

\section{Implementation}

For each application, MSAC considered the likely uptake of cascade testing and the likely uptake of prevention and treatment strategies in probands and biological relatives. Direct evidence to inform these aspects of the assessment was seldom available, necessitating the use of reasonable assumptions to inform estimates of cost-effectiveness and budget impact. The validity of these assumptions is usually tested following implementation of the corresponding MBS items, via a comparison of 'predicted' versus 'actual' utilisation of the items.

Uncertainty regarding the likely place of testing in clinical care also presented challenges for implementation. For the majority of applications, the appropriate place in care for the proposed test could be determined by triangulating clinical advice, recommendations from clinical practice guidelines, and existing subsidies for tests and treatments. But for application 1492 (NIPT), the lack of clarity regarding how the test would be implemented in the Australian health system contributed to this test not being supported for public funding. Application 1492 also presented issues regarding health system efficiency, as there was a (unresolved) tension 
between broad access to cost-ineffective testing versus targeted access to costs-effective testing for individuals at highest risk.

\section{Value assessment frameworks for genetic and genomic testing}

As shown in Fig. 2, each of the ten applications for testing for heritable conditions have used one of three available MSAC approaches. Except for the single use of the codependent technology approach for the pharmacogenomic application (1554), there is no clear pattern of use for the CUC Proforma versus the Investigative Services approach. The current plan is that key concepts from the CUC Proforma as they relate to testing for heritable conditions will be incorporated within the technical guidance for investigative services, namely, the inclusion and implications of cascade testing (including coproduction of utility), and the consideration of utility other than clinical utility.

\section{Discussion}

The aim of this paper was to review MSAC's experience in assessing genomic and genetic tests for heritable conditions and to share current thinking regarding the need for further evolution of MSAC's approach to the assessment of genetic and genomic testing. The ten applications included in this review cover a range of testing purposes: identification of congenital anomaly syndrome, genetic testing for risk of cancer, molecular diagnosis of genetic disorder, genetic risk assessment, pharmacogenomics, and carrier screening. The type of testing across these applications varied from targeted gene panels through to whole-exome sequencing and genome-wide microarray. Although efforts were made to adopt a pragmatic HTA approach a priori, none of these assessments ended up being straightforward. Challenges faced during the assessments included a lack of clarity regarding who would be tested and when and a lack of evidence for both the positive and negative impacts of testing. The uncertainty regarding the appropriate place of testing in relevant pathways of care and the clinical utility of testing lead to uncertainty in the estimations of cost-effectiveness and total budget impact. Nonetheless, despite these challenges, nine of these applications were ultimately supported by MSAC for public funding.

The approaches taken by MSAC to value genetic or genomic testing for heritable conditions are similar to assessment frameworks for 'omic' technologies used by HTA agencies around the world (Hoxhaj et al. 2020), including a focus on the link between genotype and disease, the evaluation of test performance, and the utility of testing.
Many of the challenges faced by MSAC in assessing genetic and genomic tests are not unique to Australia. For example, a systematic review of economic evaluations of NGSbased tests in Canada found there were challenges related to inconsistent approaches to the conduct and reporting of economic analyses, the uncertainty related to evidence gaps, and the lack of incorporation of non-health outcomes into economic evaluations (Weymann et al. 2019). Whilst the first of these has not been an issue in the MSAC context (each application complies with MSAC guidelines which are consistent with international standards for reporting of HTA and health economic analyses; Husereau et al. 2013; Drummond et al. 2015), the lack of key evidence and difficulties in valuing non-health benefits have been consistent challenges for MSAC.

Although the concept of clinical utility is fundamental to how MSAC assesses the value of any investigative service, MSAC has acknowledged a number of positive and negative non-health impacts of genetic and genomic testing: providing or restoring reproductive confidence; facilitating access to diagnosis-dependent educational and/or disability support; identification of disorders for which there are no prevention or treatment interventions; detection of nonpaternity, consanguinity, or incest; possible forensic uses of sequencing data; and issues around data storage and privacy. Where appropriate, MSAC sought to take these (potential) non-health outcomes into consideration when forming their overall judgement of value for a specific testing scenario. Many of these non-health impacts carry potentially significant ethical and social impacts, and the more comprehensive the sequencing, the greater the potential for ethical and social impacts. MSAC has acknowledged that it would be desirable for the societal value placed on the "value of knowing' from genetic testing to be captured more formally in future assessments.

As noted above, MSAC has a strong preference for genetic or genomic testing that yields actionable results. But consumers and clinicians differ in what they view as 'actionable': for a patient, the benefits of genomic testing can also include knowledge generated by the test that is not clinically actionable, referred to as 'personal utility' (Bombard et al. 2013; Kohler et al. 2017). Whilst Australian patient preferences for health and non-health outcomes associated with genomic testing have been reported (e.g. Goranitis et al. 2020, Goranitis et al. 2021), MSAC does not yet have preferred methods for the elicitation of such preferences, or their incorporation into MSAC assessments.

A recent systematic review of studies that valued patient preferences for NGS outcomes identified a number of methodological and conceptual challenges in the elicitation of these preferences, which they concluded were related to the breadth and complexity of information associated with NGS-directed care (Regier et al. 2018). Others have argued 
for an expanded HTA value framework that includes elements such as reduction in uncertainty, the value of hope, and the value of knowing information that might guide treatment at a future date (Garrison et al. 2017). However, the methodology for incorporating these aspects of value into an HTA is an area of active research, and possible methods such as willingness-to-pay and cost-benefit analysis are generally not preferred by MSAC. A promising concept proposed by Mighton et al. (2020) is that personal utility and clinical utility lie on a continuum, and consequently, it may be possible to apply or adapt existing quality of life measures to capture non-health outcomes from genomic testing.

A limitation of our review is that it is restricted to an analysis of information that is in the public domain, typically in the form of PSDs published on the website of the Australian Department of Health. Consequently, our analysis does not capture the perspectives of sponsors, consumers, or the contracted assessment groups regarding the challenges that these stakeholders have faced in demonstrating the value of genomic testing. The systematic collection and analysis of the perspectives of these stakeholders are an important area of future research that could inform the further evolution of MSAC's approach to the valuation of genomic testing. A strength of our review is that it identifies and systematically organises information from across multiple PSDs (which are not readily identifiable or searchable, despite being publicly available). The fact that two of the authors are members of MSAC is also a strength of the current paper: our familiarity with the ten applications as they have progressed through the assessment pathway means that we are in a unique position to identify emergent themes across the applications.

Whilst some of the findings from the current review are specific to the Australian health system (and all relate to the legislative limits on what can be listed on the MBS), the majority of findings is likely to be generalisable to other jurisdictions. Two findings that are clearly generalisable are (i) the acceptability of relying on diagnostic yield instead of sensitivity and specificity as a measure of test performance and (ii) the acceptability of relying on the cost per actionable variant or carrier couple detected instead of the cost per QALY for assessing cost-effectiveness.

\section{Conclusions}

The need for further evidence of the impact of genomic testing has been comprehensively documented by others: Phillips et al. (2017) identified many evidence gaps in comparative effectiveness research of patient-relevant outcomes for genomic medicine, and Schwarze et al. (2018) have called for more high-quality studies that carefully evaluate the cost, effectiveness, and cost-effectiveness of WES and WGS. MSAC has encountered similar evidence gaps through its consideration of genetic and genomic tests for heritable conditions. Nonetheless, despite these challenges, MSAC has exhibited a willingness to adapt its assessment approaches and accept lower evidence thresholds in particular circumstances. This pragmatic approach has been reflected in a high tolerance for uncertainty, with nine out of ten applications approved for public funding. This tolerance for uncertainty is likely related to the high unmet clinical need and low prevalence of the conditions for which testing has been approved, and the comparatively low rates of likely healthcare resource use associated with the funding approvals. By contrast, MSAC did not accept lower evidence thresholds, and associated higher levels of uncertainty, when an application was associated with a substantial budget impact (NIPT). This trade-off between a willingness to accept uncertainty and clinical need and budget impact is consistent with MSAC's general approach to HTA applications.

Acceptance of lower evidence thresholds, and higher uncertainty, is likely to have both positive and negative consequences for resource allocation. The key positive consequence of this approach is that particular genomic tests will be funded that would otherwise not be funded, thereby allowing universal access to these tests in areas of high clinical need. A key negative consequence of the approach is that some cost-ineffective tests may be funded. The risk of this occurring can be mitigated if the overall budget impact is considered alongside the estimate of cost-effectiveness, as is MSAC's usual practice. In other words, standard evidence thresholds can still be required for genomic tests that are likely to be associated with a substantial budget impact.

That said, it is clear that MSAC could further develop its approaches, to account for genomic testing for purposes other than detection of heritable conditions, and for 'omic' testing more broadly. As noted by Hoxhaj et al. (2020), it is likely that a single value assessment framework may be too general to apply to all possible clinical scenarios (i.e. screening, diagnosis, prognosis, monitoring, or predictive testing) or to all molecular techniques. This has certainly been the experience of MSAC, where the 'exemplar/facilitated' approach for targeted gene panels was not appropriate for carrier screening or identification of congenital anomaly syndromes and was not feasible for large gene panels or WES. Additionally, whilst a focus on clinical management and health outcomes is necessary, it is not always sufficient to fully value the non-health impacts of genomic testing for individuals, their family members, and society more broadly. Research is needed to explore how patient and societal preferences for the health and non-health outcomes of genomic testing (e.g. Mighton et al., 2020; Goranitis et al. 2020) and different evidence thresholds for genomic medicine (e.g. Guzauskas et al., 2019) could be formally incorporated within the value assessment framework used by MSAC for genomic testing. 
Author contribution Robyn Ward and Sarah Norris were responsible for study conception and design. Material preparation, data collection, and analysis were performed by Andrea Belcher and Sarah Norris. The first draft of the manuscript was written by Sarah Norris, and all authors commented on previous versions of the manuscript. All authors read and approved the final manuscript. The views expressed in the paper are not those of the Commonwealth Government of Australia.

Funding Sarah Norris, Andrea Belcher and Robyn Ward were supported to undertake this research by funding to the Australian Genomics Health Alliance from the Australian National Health and Medical Research Council (NHMRC) (Grant GNT1113531).

Data availability The data summarised in this article are available in public summary documents (PSDs) published on the Medical Services Advisory Committee website. A link to each PSD relied on is provided within the article.

\section{Declarations}

Human and animal rights consent This article does not contain any studies with human or animal subjects performed by the any of the authors.

Conflict of interest Andrea Belcher has no Conflicts of Interest. Robyn Ward and Sarah Norris are members of the Medical Services Advisory Committee (MSAC) and each is involved with the current review and update of the MSAC Technical Guidelines. Kirsten Howard is a member of the Pharmaceutical Benefits Advisory Committee (PBAC). Robyn Ward, Kirsten Howard, and Sarah Norris receive sitting fees from the Australian Commonwealth Department of Health for their role on PBAC and MSAC.

Open Access This article is licensed under a Creative Commons Attribution 4.0 International License, which permits use, sharing, adaptation, distribution and reproduction in any medium or format, as long as you give appropriate credit to the original author(s) and the source, provide a link to the Creative Commons licence, and indicate if changes were made. The images or other third party material in this article are included in the article's Creative Commons licence, unless indicated otherwise in a credit line to the material. If material is not included in the article's Creative Commons licence and your intended use is not permitted by statutory regulation or exceeds the permitted use, you will need to obtain permission directly from the copyright holder. To view a copy of this licence, visit http://creativecommons.org/licenses/by/4.0/.

\section{References}

Australian Government Department of Health (2020) Health technology assessment. https://www1.health.gov.au/internet/hta/publi shing.nsf/Content/home-1 Accessed 19 May 2021

Banta D, Jonsson E (2009) History of HTA: introduction. Int J Technol Assess Health Care 25(S1):1-6

Bombard Y, Bach PB, Offit K (2013) Translating genomics in cancer care. J Natl Compr Canc Netw 11(11):1343-1353

Burke W, Atkins D, Gwinn M, Guttmacher A, Haddow J, Lau J, Palomaki G, Press N, Richards CS, Wideroff L (2002) Genetic test evaluation: information needs of clinicians, policy makers, and the public. Am J Epidemiol 156(4):311-318

Cornel MC, Rigter T, Jansen ME, Henneman L (2021) Neonatal and carrier screening for rare diseases: how innovation challenges screening criteria worldwide. J Community Genet 12(2):257-265. https://doi.org/10.1007/s12687-020-00488-y

Drummond MF, Sculpher MJ, Claxton K, Stoddart GL, Torrance GW (2015) Methods for the economic evaluation of health care programmes. Oxford University Press

EUnetHTA (2016) HTA Core Model ${ }^{\circledR}$ version 3.0. https://www.eunet hta.eu/wp-content/uploads/2018/03/HTACoreModel3.0-1.pdf. Accessed 8 Feb 2021

Garrison LP Jr, Kamal-Bahl S, Towse A (2017) Toward a broader concept of value: identifying and defining elements for an expanded cost-effectiveness analysis. Value in Health 20(2):213-216

Goranitis I, Best S, Christodoulou J, Stark Z, Boughtwood T (2020) The personal utility and uptake of genomic sequencing in pediatric and adult conditions: eliciting societal preferences with three discrete choice experiments. Genet Med 22(8):1311-1319

Goranitis I, Best S, Stark Z, Boughtwood T, Christodoulou J (2021) The value of genomic sequencing in complex pediatric neurological disorders: a discrete choice experiment. Genet Med 23(1):155-162

Guzauskas GF, Basu A, Carlson JJ, Veenstra DL (2019) Are there different evidence thresholds for genomic versus clinical precision medicine? A value of information-based framework applied to antiplatelet drug therapy. Value in Health 22(9):988-994

Hoxhaj I, Govaerts L, Simoens S, Van Dyck W, Huys I, GutiérrezIbarluzea I, Boccia S (2020) A systematic review of the value assessment frameworks used within health technology assessment of omics technologies and their actual adoption from HTA agencies. Int J Environ Res Public Health 17(21):8001

Husereau D, Drummond M, Petrou S, Carswell C, Moher D, Greenberg D, Augustovski F, Briggs AH, Mauskopf J, Loder E (2013) Consolidated health economic evaluation reporting standards (CHEERS) statement. Eur J Health Econ 14(3):367-372

Kohler JN, Turbitt E, Biesecker BB (2017) Personal utility in genomic testing: a systematic literature review. Eur J Hum Genet 25(6):662-668

Korf BR, Irons MB (2012) Human genetics and genomics. John Wiley \& Sons

Medical Services Advisory Committee (2013) Application No. 1250. Testing of the ALK gene in tumour material from patients with non-small cell lung cancer to determine eligibility for treatment with crizotinib. Department of Health. http://www.msac.gov.au/ internet/msac/publishing.nsf/Content/1250-public. Accessed 14 Jan 2021

Medical Services Advisory Committee (2014) Application No. 1363. RAS (KRAS and NRAS) mutation testing for eligibility to access panitumumab. Department of Health. http://www.msac.gov.au/ internet/msac/publishing.nsf/Content/1363-public. Accessed 14 Jan 2021

Medical Services Advisory Committee (2015a) Application 1165. Preimplantation genetic diagnisis (PGD) assessment. Department of Health. http://www.msac.gov.au/internet/msac/publishing.nsf/ Content/1165-public. Accessed 14 Jan 2021

Medical Services Advisory Committee (2015b) Application 1216. Cystic fibrosis transmembrane regulator (CFTR) testing. Department of Health. http://www.msac.gov.au/internet/msac/publi shing.nsf/Content/1216-public. Accessed 14 Jan 2021

Medical Services Advisory Committee (2016a) Clinical utility card for heritable mutations which increase risk in disease. Department of Health. http://www.msac.gov.au/internet/msac/publishing.nsf/ Content/applicants. Accessed 14 Jan 2021

Medical Services Advisory Committee (2016b) Application No. 1411.1. Genetic testing for hereditary mutations predisposing to 
cancer (breast and/or ovarian). Department of Health. http://www. msac.gov.au/internet/msac/publishing.nsf/Content/1411.1-public. Accessed 14 Jan 2021

Medical Services Advisory Committee (2017) Technical guidelines for preparing assessment reports for the medical services advisory committee - service type: investigative (Version 3.0). Department of Health. http://www.msac.gov.au/internet/msac/publishing.nsf/ Content/applicants. Accessed 14 Jan 2021

Medical Services Advisory Committee (2018a) Application No. 1449. Genetic testing for Alport syndrome. Department of Health. http:// www.msac.gov.au/internet/msac/publishing.nsf/Content/1449Public. Accessed 14 Jan 2021

Medical Services Advisory Committee (2018b) Application No. 1504. Heritable mutations which increase risk in colorectal and endometrial cancer. Department of Health. http://www.msac.gov.au/ internet/msac/publishing.nsf/Content/1504-public. Accessed 14 Jan 2021

Medical Services Advisory Committee (2019a) Application No. 1476. Genetic testing for childhood syndromes. Department of Health. http://www.msac.gov.au/internet/msac/publishing.nsf/Content/ 1476-public. Accessed 14 Jan 2021

Medical Services Advisory Committee (2019b) Application No. 1492. Non-invasive prenatal testing (NIPT) for trisomies 21, 18 and 13. Department of Health. http://www.msac.gov.au/internet/msac/ publishing.nsf/Content/1492-public. Accessed 14 Jan 2021

Medical Services Advisory Committee (2019c) Application No. 1533. Genome-wide microarray testing for pregnancies with major fetal structural abnormalities detected by ultrasound. Department of Health. http://www.msac.gov.au/internet/msac/publishing.nsf/ Content/1533-public. Accessed 14 Jan 2021

Medical Services Advisory Committee (2019d) Application No. 1534. Heritable mutations associated with familial hypercholesterolaemia. Department of Health. http://www.msac.gov.au/internet/ msac/publishing.nsf/Content/1534-public. Accessed 14 Jan 2021

Medical Services Advisory Committee (2019e) Application No. 1554. Testing of tumour tissue or blood to detect somatic or germline BRCA1 or BRCA2 gene mutations, in a patient with newly diagnosed, advanced (FIGO stage III-IV) high-grade epithelial ovarian, fallopian tube or primary peritoneal cancer who are in response (complete or partial) to first-line platinum-based chemotherapy). http://www.msac.gov.au/internet/msac/publishing.nsf/ Content/1554-public. Accessed 14 Jan 2021

Medical Services Advisory Committee (2020a) Application No. 1573. Reproductive carrier screening for fragile X syndrome, spinal muscular atrophy and cystic fibrosis. Department of Health.
http://www.msac.gov.au/internet/msac/publishing.nsf/Content/ 1573-public. Accessed 14 Jan 2021

Medical Services Advisory Committee (2020b) Application No. 1598. Genetic testing for diagnosis of inheritable cardiac rhythm disorders. Department of Health. http://www.msac.gov.au/internet/ msac/publishing.nsf/Content/1598-public. Accessed 26 Apr 2021

Mighton C, Carlsson L, Clausen M, Casalino S, Shickh S, McCuaig L, Joshi E, Panchal S, Semotiuk K, Ott K (2020) Quality of life drives patients' preferences for secondary findings from genomic sequencing. Eur J Hum Genet 28(9):1178-1186

O'Rourke B, Oortwijn W, Schuller T (2020) The new definition of health technology assessment: a milestone in international collaboration. Int J Technol Assess Health Care 36(3):187-190

Phillips KA, Deverka PA, Sox HC, Khoury MJ, Sandy LG, Ginsburg GS, Tunis SR, Orlando LA, Douglas MP (2017) Making genomic medicine evidence-based and patient-centered: a structured review and landscape analysis of comparative effectiveness research. Genet Med 19(10):1081-1091. https://doi.org/10.1038/ gim.2017.21

Phillips KA, Deverka PA, Marshall DA, Wordsworth S, Regier DA, Christensen KD, Buchanan J (2018) Methodological issues in assessing the economic value of next-generation sequencing tests: many challenges and not enough solutions. Value in Health 21:1033-1042. https://doi.org/10.1016/j.jval.2018.06.017

Regier DA, Weymann D, Buchanan J, Marshall DA, Wordsworth S (2018) Valuation of health and nonhealth outcomes from nextgeneration sequencing: approaches, challenges, and solutions. Value in Health 21(9): 1043-1047

Schmidtke J, Cassiman J-J (2010) The EuroGentest clinical utility gene cards. Eur J Hum Genet 18(9):1071-1071. https://doi.org/ 10.1038/ejhg.2010.85

Schwarze K, Buchanan J, Taylor JC, Wordsworth S (2018) Are wholeexome and whole-genome sequencing approaches cost-effective? A systematic review of the literature. Genet Med 20(10):11221130. https://doi.org/10.1038/gim.2017.247

Weymann D, Dragojlovic N, Pollard S, Regier DA (2019) Allocating healthcare resources to genomic testing in Canada: latest evidence and current challenges. Journal of community genetics:1-10

Publisher's note Springer Nature remains neutral with regard to jurisdictional claims in published maps and institutional affiliations. 